\title{
An Experimental Approach to the Sophomore Architectural Design Studio
}

\author{
Milorad Pavlovic \\ Faculty of Architecture, Alanya Hamdullah Emin Pasa University, Alanya, 07400, Turkey
}

Received August 20, 2020; Revised September 14, 2020; Accepted September 21, 2020

\section{Cite This Paper in the following Citation Styles}

(a): [1] Milorad Pavlovic, "An Experimental Approach to the Sophomore Architectural Design Studio," Civil Engineering and Architecture, Vol. 8, No. 5, pp. 942 - 949, 2020. DOI: 10.13189/cea.2020.080521.

(b): Milorad Pavlovic (2020). An Experimental Approach to the Sophomore Architectural Design Studio. Civil Engineering and Architecture, 8(5), 942 - 949. DOI: 10.13189/cea.2020.080521.

Copyright $\mathrm{O} 2020$ by authors, all rights reserved. Authors agree that this article remains permanently open access under the terms of the Creative Commons Attribution License 4.0 International License

\begin{abstract}
Architectural education is widely dominated by design studio courses. Their organization and development constitute an open challenge for educators due to the complexity of the participating factors, i.e., teaching method, design topics, assignments, expected learning outcomes, and experimentation. In particular, the organization might be considered as the factor that characterizes the whole process of the design studio course in different forms. In this research, an experimental approach based on 3 project assignments has been proposed for the sophomore design studio courses, as an alternative to the common practice of single project assignment per semester. The procedure aims on proposing a method that allows the students to maintain the organizational schemes of the freshman courses and increase their competences constantly and progressively. The process has been implemented during the fall semester 2019 and applied in the Architectural Design Studio 1 at Alanya Hamdullah Emin Pasa University, Department of Architecture, program in the English language. At the conclusion of the experiment, a questionnaire for the students has been conducted. The paper presents the organizational model proposed, the results of the questionnaire, observations of the lecturer, and discusses the reliability of the proposed method.
\end{abstract}

Keywords Architecture, Architectural
Architectural Eesign,
Experimental Model

\section{Introduction}

\subsection{Historical Background}

It's well known that the Design Studio course plays a primary role in architectural education. Due to its character of learning-by-doing and the highest number of credits that usually deserve, this course commits most hours of the students' weekly workload. Another peculiar characteristic of the design studio course is being flanked by the supportive courses. Such courses, mainly with theoretic character, provide students specific knowledge on single subjects (such as history and theory, technology and materials, structural principles, etc.) whereas in the design studio courses the knowledge acquired from different disciplines should come together across the design studio problem. This heterogeneous character of the Design Studio course is also at the base of its complex social and cultural aspects $[1,2]$. Nevertheless, the role played by the critiques and the juries should be omitted as a fundamental part of architectural education [3, 4].

Historically, the character of learning-by-doing was particularly enhanced since the central core of architectural education was the master-apprentice relation based on the atelier's environment [5]. The center of education remained at the atelier also at the beginning of the 20th century, with Bauhaus institution [6], however, it has been only in the years 1980's that present day's model of studio-based design instruction has been defined [7,8]. Such model, adopted for decades, became the emblem of architectural education, widely adopted. Among the researchers developed in further years, that focused on its 
adaptation, can be highlighted the proposal of defining an educational program based on 2 contemporary studios [9] and the role of CAD applications [10].

\subsection{Present Day's Educational Problems}

From a review of the technical-scientific literature, it may be assumed that, at present days, there is no consensus agreed upon the methodological and pedagogical approaches to be practiced in an architectural design studio course. The organizational problem remains among the open debates [11-13], as well as the option of approaches involving the creative, critical and pragmatic thinking [14-16], the communication techniques [10], the value of sketches and hand drawings [17-18], and the grading issues [19-20].

Accordingly to this review, can be observed the need of providing models that can improve the existing approaches. In particular, the new paradigm proposed by Wang [14] seeks to provide the rigor that is lacking in design education. On the other hand, the model proposed by Ciravoğlu [13], proposes a solution to overcome the master-apprentice condition, whereas the research proposed by Pasin [21] discusses the central role of the design studio in contemporary teaching methods. Similarly, in the author's opinion, proposals for organizational models are worth of recommendations, not only for a single course but also for the teaching and methodological continuity in between courses. In particular, this research intends to propose an organizational model that considers the general aspects of the freshmen studio courses and suggests a continuity for the sophomore level.

\subsection{Problems Examined in the Context of the Research}

Observing the participating factors involved in a design studio course (Figure 1), the present research intends to focus on the problems of course organization, design topic, and assignments. One of the reasons is that, for such matters, the available literature is limited and the choice of the topics is mostly related to the lecturer's choice or based on the own experiences [22, 23]. Another reason derives from the observations on the existing practices of studio course management, and prerequisite relations. As in many programs design studio courses are following the prerequisite requirements, reasons for which students need to complete the courses progressively, however not always this progress corresponds to continuity in terms of pedagogy and methodology. Often for the students starting a new design studio course mean developing different working methods and different approaches. Therefore, the common feeling is of starting every time from zero, with limited possibilities of transmitting the knowledge acquired previously to the next levels.

As still there's no unanimous consensus about design topics to be proposed at each level, the residential topic is often considered the less complex and frequently assigned to the novice students. Hence, the solution of a residential problem has been considered as a tool for design, with particular attention on providing the students' abilities and knowledge for solving the proportions and relations of the interior and exterior designed spaces. Relations, those students generally examine during the freshmen year [24]. Thus, the research addresses a method for sophomore students, which allows them to maintain the general organization of the Basic Design courses as well as the notions acquired in the course of Introduction to Architectural Design. Additionally, the model intends to propose new elements, such as building typologies, construction materials, and contemporary structural systems.

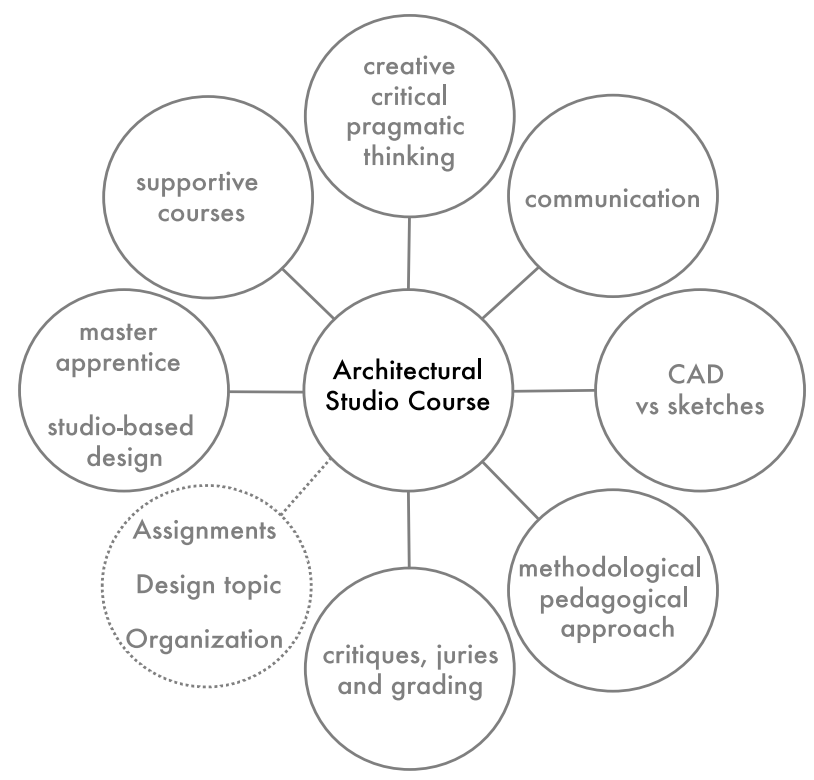

Figure 1. Contextualization of the research

Therefore, in the present research, an organizational model for the sophomore studio course has been proposed that considers: i) a 15 weeks semester; ii) 3 project assignments; iii) Basic Design and Introduction to Architectural Design Courses completed during the freshman year. The model aims on overcoming the consolidated practice of assigning one project per semester and allowing students to: i) acquire the knowledge by practicing gradually and additionally; ii) to manage the time properly; iii) to perform research work as a form of self-critiques activity. The course model has been applied during the fall semester 2019 in the Architectural Design Studio 1 at Alanya Hamdullah Emin Pasa University, Department of Architecture, program in the English language.

\section{Materials and Methods}

Starting from the considerations mentioned above, an experimental approach to the sophomore design studio course has been developed. The model considers a 15 
weeks semester, 3 projects development, 3 juries, and enhances activities such as lectures and different forms of critiques (collective and individual). In particular, the choice of assigning 3 design solutions derives from the observation of the previous experiences. It has been noticed that with the common practice of assigning 1 project per semester, generally, students exhibit a disconnected trend regarding the course participation, as well as dedication on a project solution. One of the reasons, in the author's opinion, might be attributed to the long period that occurs between the conceptual sketches and final presentation. Therefore, a model for the studio organizations has been proposed with the aim of providing students more stimuli and possibilities to examine a completed project in a relatively short time (5 weeks).

\subsection{Organizational Model}

The course has been organized accordingly to a schedule of 15 weeks divided into 3 steps of 5 weeks each. Each step consisted of 4 lecture-critiques weeks and 1 jury week. For each step, a different topic has been defined: 1st step development of the patio house typology; 2nd step development of the row house typology; 3rd step development of the villa typology. The sequence of the topics has been proposed to increase, step by step, the complexity level of the designed environments, and their relations.

Since a patio house (or a courtyard house) can be considered an intrinsic residential unit, with patio as the focal point for all the activities, the attention during the critiques has been mainly oriented toward 3 points: i) human scale; ii) in plan design relations between the main spaces and service spaces; iii) visual relations between each patio and related interior areas. Further considerations involved the usage of auxiliary devices, aimed at improving the privacy of the occupants or the extensions of the activities among the open, semi-open, and closed spaces.

As the next step, with the row house typology, the 3rd dimension and the vertical relations have been enhanced in the progress of development. Here, additionally to the previously examined topics, the role of the staircase, as an element for both service function and space organization, has been considered. Differently from the previous study case, the students were invited to consider the design of the elevations, rather than simply extrude them from plans, introducing the concepts of shading and the usage of materials.
Successively, with the villa typology, the problem of solving a residential unit has been shifted, from the planimetric to the volumetric approach. Here the students were invited to invert the design trend (plans, sections, elevations, 3D models), starting from the volumetric approach, passing through the sections and elevations design, and verifying the functions through plan design. Differently from the previously designed typologies, the problem of the functions solutions has been significantly extended, considering the design of the exterior spaces as: i) extensions of the living area; ii) additional utilitarian spaces; iii) environments designed for leisure activities.

As one of the essential components of design education is represented by the critiques, during the studio course the students' progress has been checked both collectively and individually. Initially, the critiques were done as a table discussion, involving 8-10 students at the time. The process is intent to highlight the common mistakes both in terms of design solutions and graphical representation. Successively, the critiques were held in the 1 to 1 manner, in order to focus on each project and examine the own potential. Since the course was given once a week with a schedule of 8 hours and a ratio lecturer/students of $1 / 15$, most of the time it was possible to check the students' progress twice per day. Besides the critiques, theoretical lectures were performed to focus the attention on specific questions that emerged during the project developments. In particular, the lectures focused on: i) model-making techniques; ii) advanced graphical representation and, iii) study case critical analyses.

To evaluate the progress and the overall performance of the students, 2 intermediate juries and a final one have been defined. For both the intermediate juries, students were requested to present besides their project solutions, a research work consisting of critical analyses of architectural examples related to the topic. Hence, theoretical research was integrated into the design process. For the final jury, besides the development of the villa project and the relative research work, the students were requested to improve the previously designed typologies accordingly to the critiques received during the juries. Therefore the design process for each typology continued till the end of the course, highlighting the progress achieved during the course. Figure 2 summarizes the proposed model. The abbreviations are reassumed as follows: $\mathrm{w}=$ week; $\mathrm{L}=$ lecture; $\mathrm{cc}=$ collective critiques; ic = individual critiques; $\mathrm{J} 1, \mathrm{~J} 2=$ intermediate juries; $\mathrm{FJ}=$ final jury. 


\section{5 weeks}

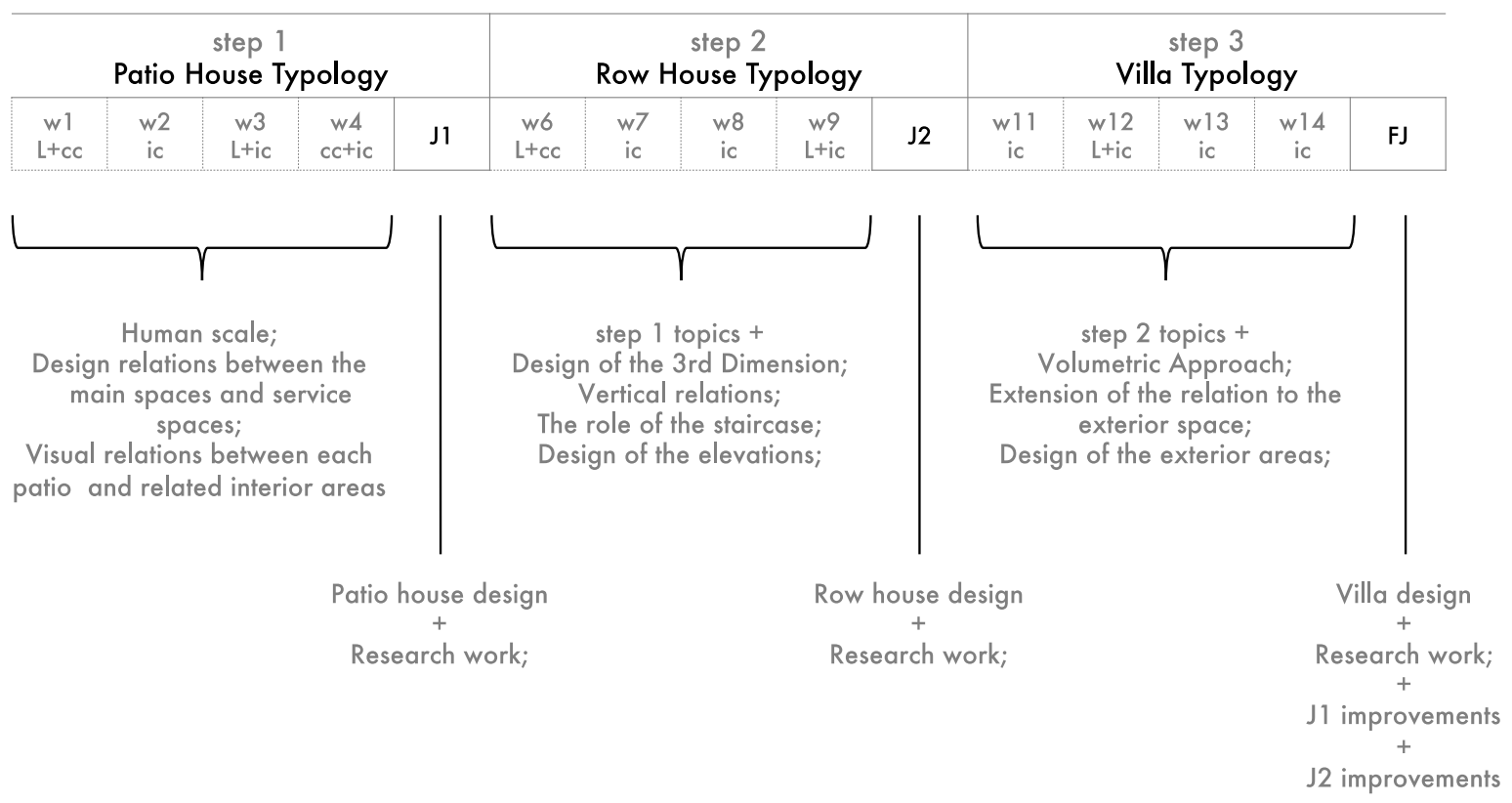

Figure 2. Course organization summary

\section{Results}

At the conclusion of the experiment, with the aim of verifying the proposed model, a questionnaire has been prepared and submitted to 30 students who attended the course. Considering that the course was the first studio experience for most of the students (after the freshmen courses), it was particularly important to understand also how the lectures and the knowledge have been transmitted.

As well known, questionnaires can be considered as valid collection tools for quantitative researchers [25]. Their reliability and efficiency is widely discussed in technical/scientific literature and several models can be applied for the analyses in higher education [26-28]. In particular, for the present research the methods that involve College Student Experiences Questionnaire [29] and the Course Perception Questionnaire [30] have been considered. Hence, a questionnaire has been arranged including 3 sets of questions. For each question, a scale from 1 to 5 has been to order to express the level of agreement.

The 1st set of questions aimed at the evaluation of the course objectives, time organization, and the students' contribution. The 2 nd set of questions indented to examine the efficiency of the learning environment, teaching methods, and learning resources. Lastly, the 3rd set of questions aimed at the evaluation of the quality of delivery and gave the possibility to the students to suggest the improvement and criticize the features.

Accordingly, to the answers of the students, the absolute majority agreed that the course objectives were clear (Figure 3, A1), that the course workload was manageable (Figure 3, A2) and that class time was well organized (Figure 3, A3). Still, nearly the totality of the students agreed on the fact that they participate actively in the course (Figure 4, B1) and that they made progress (Figure 4, $\mathrm{B} 2)$.

The 2nd set of questions aimed at the examination of the learning environment and learning resources. Here, a low percentage of the students disagreed with the proposed model in terms of achieving the learning outcomes (Figure $5, \mathrm{C} 1$ ) and with the fact that the overall environment was conducive to learning (Figure 5, C3). However, none of the students argued that the teaching methods didn't encourage participation (Figure 5, C2).

More differentiated answers of the students have been collected throughout the answers on the questions related to the learning resources adopted. Here the majority of the students agreed on preferring internet as the main source of the materials (Figure 6, D4), rather than the course materials (Figure 6, D1), suggested textbooks (Figure 6, D2) and the hard-copy library sources (Figure 6, D3).

The 3rd set of questions aimed at examining the quality of delivery. Here, generally, more than $80 \%$ of the students agreed that the course stimulated their interest on the subject (Figure 7, E1), that the pace of the course was appropriate (Figure 7, E2) and that the concepts and ideas were presented and discussed clearly (Figure 7, E3).

As the last open-ended inquiry of the questionnaire, the students were asked for the suggestion and improvements of the course model. Accordingly to the answers, some of the students consider the studio course as an opportunity to improve their $\mathrm{CAD}$ and image elaboration skills. For some others, a higher number of architectural examples should have been examined during the theoretical lectures, whereas no negative comment about the time organization and the learning method has been recorded. 
A1

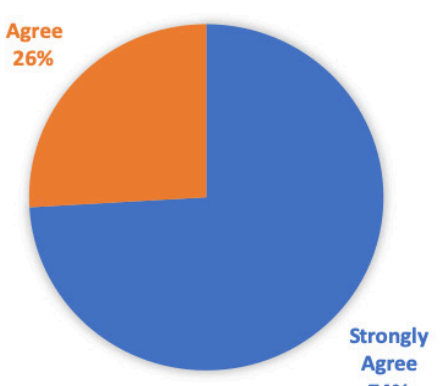

$\mathbf{7 4 \%}$
A2

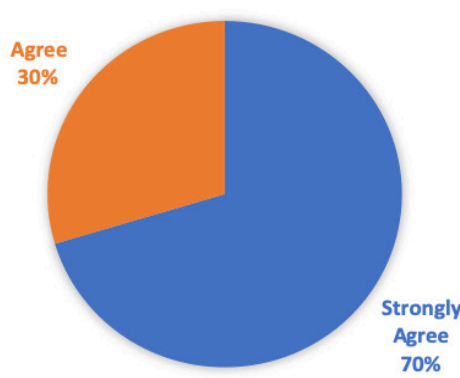

A3

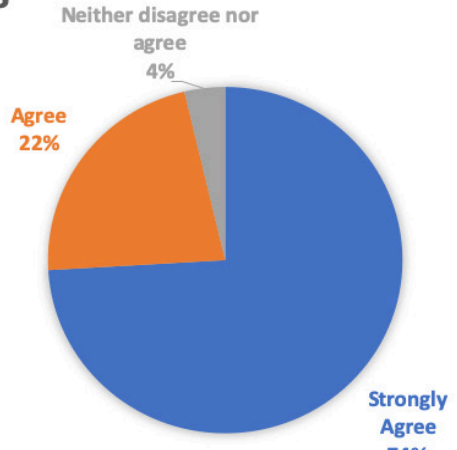

Figure 3. Objectives of the course

B1

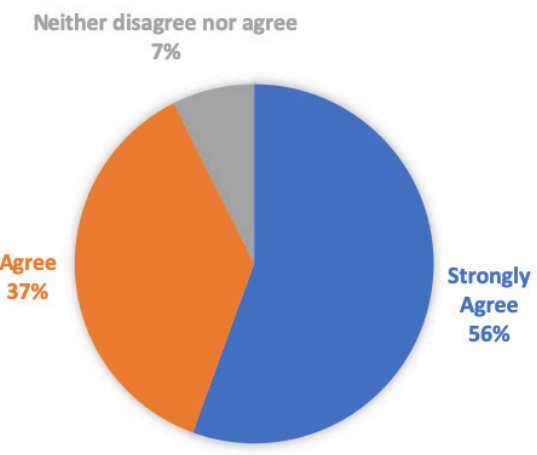

B2

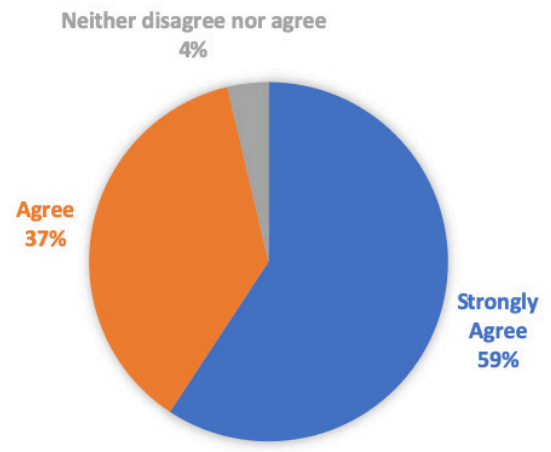

Figure 4. Student contribution

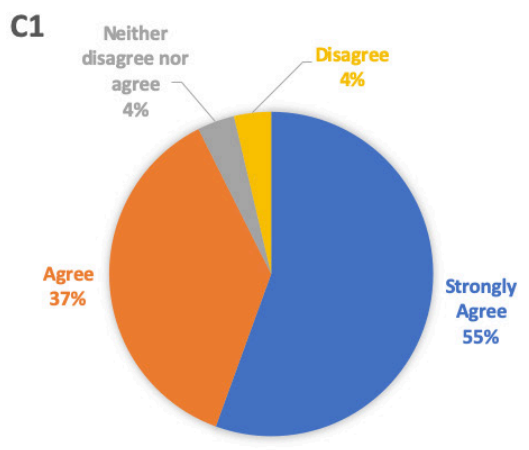

C2

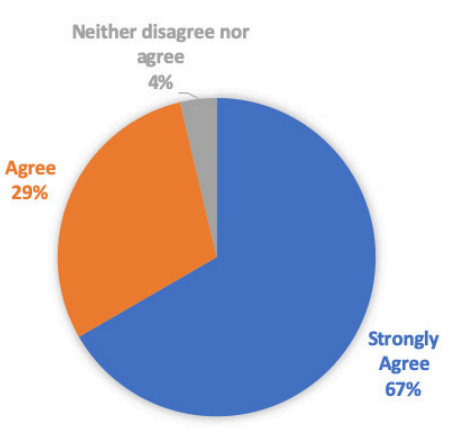

C3

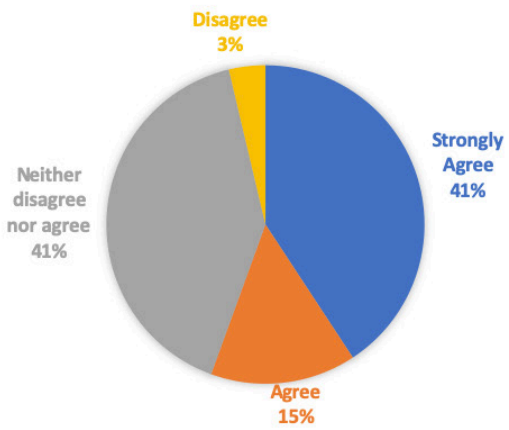

Figure 5. Learning environment and teaching methods 
D1

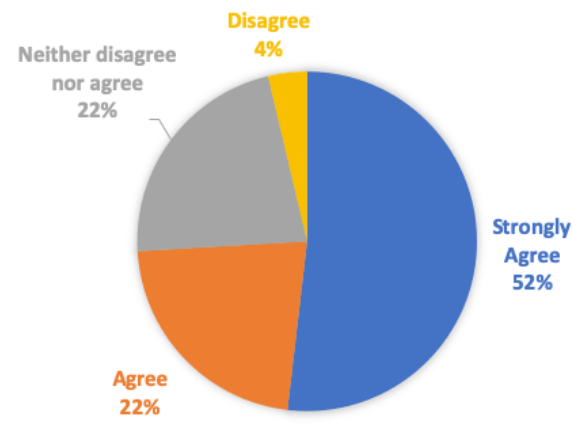

D3

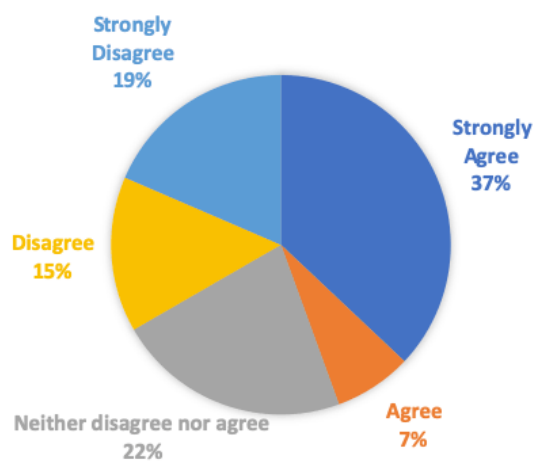

D2

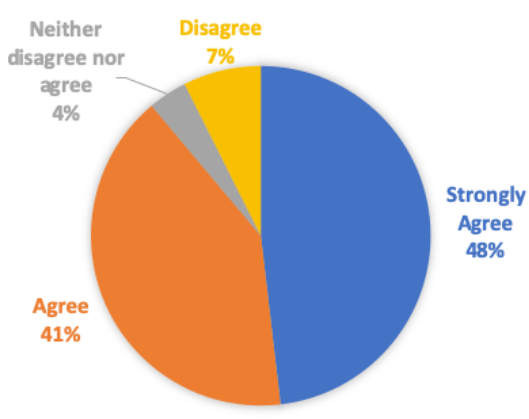

D4

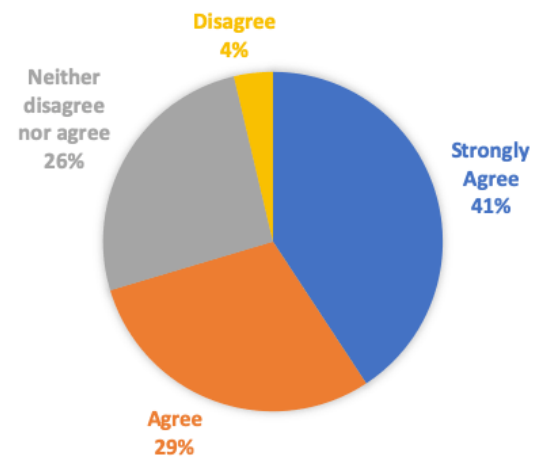

Figure 6. Learning Resources

E1

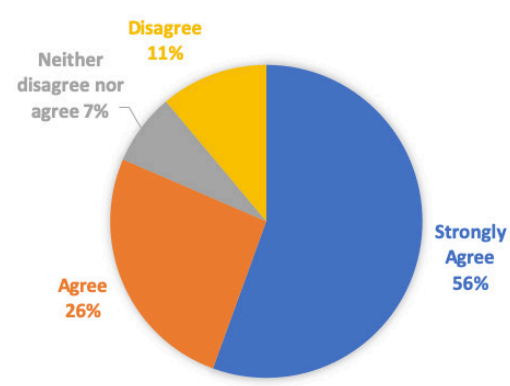

\section{Discussion}

\subsection{Questionnaire's Observations}

As regards the results of the questionnaire it can be assumed that the students who participated found the model suitable in all the aspects: time organizations, teaching methods, and quality of delivery. In particular, the absolute majority of agreements have been recorded for the 1 st and the 3rd sets of questions, whereas the 2 nd set registered a higher level of disagreements. Here, the highest level of argument (34\%) has been recorded regarding the usage of textbooks and hardcopies as course materials. This aspect may suggest the almost total usage of the internet as the main source of examples and learning materials preferred by the students.
E2

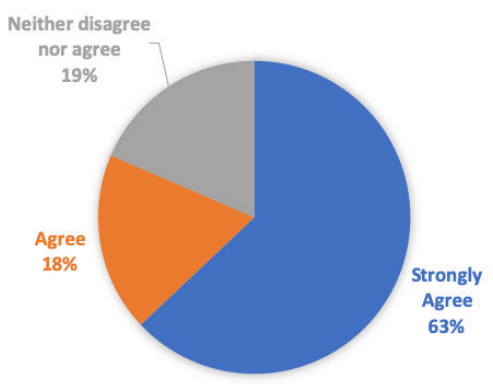

E3

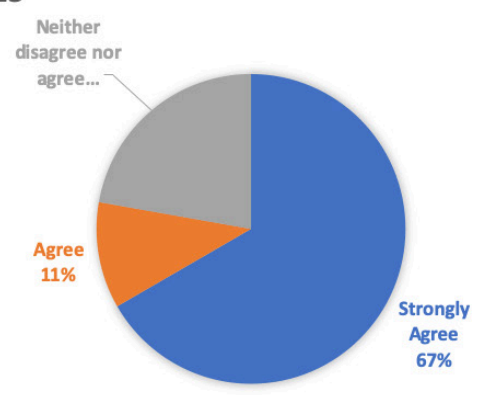

Figure 7. Quality of delivery

\subsection{Lecturer's Opinions}

Considering the progress and the achievements of the course, in the author's opinion can be outlined that the division of the course into 3 sessions, each with the own topic, allowed students to concentrate on the solution of a single problem at the time. Hence, this approach might be considered suitable for the sophomore students since it allows the possibility of facing the architectural problem solution step by step. By proceeding in this manner, difficulties and errors faced in the beginning, have the chance to be overcome in the following steps. For instance, once the problem of human scale, dimensional requirements, and proportions of the spaces have been solved for the 1st residential typology, its application becomes smoother in the following one, and the progress of 
architectural design solutions can be implemented by further tasks.

Furthermore, for the first two typologies, the students principally exhibit the trend of solving the problem for the sequence plans, sections, elevations, 3D models, whereas, with the villa typology the requirements and the analyses have been redefined considering the architectural solution as a volumetric entity. With a background of the bidimensional organization, it became reliable for the students to consider both the aesthetic and functional aspects.

Besides the development of the individual design, during the course, theoretical lectures and research works were performed as supportive activities. In particular, has been observed that the comparison of their design with emblematic architectural projects suggested students a pathway for improvement. Therefore, the research activity assumed the role of a self-critique tool.

Lastly, the relatively short time of 5 weeks for each step culminating with a jury, suggested students to properly manage their time. As a result, the response of the students to the space organization's design problem generally came smoother rather than in a studio course based on one-project solution per semester. However, besides the pace that seemed working properly for the management of the course some difficulties characterized the students' performance. The difficulties involved design aspects (space organizations, graphic representation), as well as the personal approach (self-initiative for design solutions, and differentiated level of attention for different representations). Difficulties, that from an objective evaluation, might be considered common for novice students.

\section{Conclusions}

In the present research, a model for the sophomore architectural design studio course has been proposed. The model intends to propose an alternative solution for the consolidated practice of assigning 1 project per semester. Therefore a model, based on 3 design problems and relative juries has been defined. The procedure aspires on allowing students to: i) acquire the knowledge by practicing gradually and additionally; ii) to manage the time properly; iii) to perform research work as a form of self-critiques. The procedure has been applied during the fall semester 2019 in the Architectural Design Studio 1 at Alanya Hamdullah Emin Pasa University, Department of Architecture, and program in the English language.

To evaluate the performance of the course, a questionnaire constituted by 3 sets of questions has been submitted to the students for the evaluation. As result, the questionnaire recorded high levels of agreement for all the groups of questions, which might suggest the efficiency and the appreciation of the method. Still, in the author's opinion, the course promoted a good pace and reached a satisfactory level of results. However, since the procedure has been applied only once, to understand its reliability it would be beneficial to apply the model to a higher number of participants, preferably with a different background.

\section{Acknowledgements}

I would like to express my gratitude to Arch. Betül Akın Güngör for the helpful cooperation during the critiques and the juries. Likewise, I acknowledge my colleagues from Basic Design Studio courses Dr. Evren Ülkeryıldız and Dr. Nihan Kocaman Pavlovic for the continuous exchange of ideas and suggestions. Lastly, I would like to thank all the students who participated in the course and the survey.

\section{REFERENCES}

[1] M. P. Frederickson. Design Juries: A Study in Lines of Communication, Journal of Architectural Education, Vol.43, No.2, 22-27.

[2] J. K. Ochsner. Behind the Mask: A Psychoanalytic Perspective on Interaction in the Design Studio, Journal of Architectural Education, Vol.53, No.4, 194-206.

[3] M. P. Frederickson. Gender and Racial Bias in Design Juries, Journal of Architectural Education, Vol.47, No.1, 38-48.

[4] G. Scagnetti. A dialogical model for studio critiques in Design Education, The Design Journal, Vol.20, No.1, 781-791.

[5] G. Goldschmidt, H. Hochman, I. Dafni. The design studio 'Crit:' Teacher-student Artificial Intelligence for Engineering Design, Analysis and Manufacturing, Vol.24, No.3, 285-302.

[6] F. Lerner. Foundations for Design Education: Continuing the Bauhaus Vorkurs Vision, Studies in Art Education, Vol.46, No.3, 211-226.

[7] D. A. Schön, V. DeSanctis. The Reflective Practitioner: How Professionals Think in Action, The Journal of Continuing Higher Education, Vol.34, No.3, 29-30.

[8] D. A. Schön. Toward a Marriage of Artistry \& Applied Science in the Architectural Design Studio, Journal of Architectural Education, Vol.41, No.4, 4-10.

[9] E. Allen. Second Studio: A Model for Technical Teaching, Journal of Architectural Education, Vol.51, No.2, 92-95.

[10] B. Uluoğlu. Design knowledge communicated in studio critiques, Design Studies, Vol.21, No.1, 33-58.

[11] K. Brocato. Studio Based Learning: Proposing, Critiquing, Iterating Our Way to Person-Centeredness for Better Classroom Management, Theory Into Practice, Vol.48, No.2, 138-146.

[12] C.B. Brandt, K. Cennamo, S. Douglas, M. Vernon, M. McGrath, Y. Reimer. A theoretical framework for the studio 
as a learning environment, Int J Technol Des Educ, Vol.23, No.2, 329-348.

[13] A. Ciravoğlu. Notes on Architectural Education: An Experimental Approach to Design Studio, Procedia - Social and Behavioral Sciences, Vol.152, 7-12.

[14] T. Wang. A New Paradigm for Design Studio Education, International Journal of Art \& Design Education, Vol.29, No. 2, 173-183.

[15] R. Hargrove. Fostering creativity in the design studio: A framework towards effective pedagogical practices, Art, Design \& Communication in Higher Education, Vol.10, No. 1, 7-31.

[16] N. L. Nik Ibrahim, N. Utaberta. Learning in Architecture Design Studio, Procedia - Social and Behavioral Sciences, Vol.60, 30-35.

[17] Z. Bilda, J. S. Gero, T. Purcell. To sketch or not to sketch? That is the question, Design Studies, Vol.27, No. 5, 587-613.

[18] G. Goldschmidt. Manual Sketching: Why Is It Still Relevant?, Philosophy of Engineering and Technology, Vol. $28,77-97$.

[19] Ş. Çıkıș, E. Çil. Problematization of assessment in the architectural design education: First year as a case study, Procedia - Social and Behavioral Sciences, Vol. 1, No. 1, 2103-2110

[20] O. A. Alagbe, A. A. Oluwatayo, P. A. Aderonmu, G. M. Alalade. Difference in grading parameters in architectural schools and its impact on the competency rating of future professionals, Frontiers of Architectural Research, Vol. 4, No. 3, 230-236.

[21] B. Pasin. Rethinking the Design Studio-Centered Architectural Education. A Case Study at Schools of
Architecture in Turkey, The Design Journal, Vol. 20, No. 1, 1270-1284.

[22] S. I. Dizdar. Architectural Education, Project Design Course and Education Process Using Examples, Procedia - Social and Behavioral Sciences, Vol. 176, 276-283.

[23] S. Ashraf. A Process Oriented Design Pedagogy: KFUPM Sophomore Studio, CEBE Transactions, Vol. 2, 16-31.

[24] P. Sarioglu. Basic Design Education: A course outline proposal, Journal of Planning, Vol. 26, No. 1, 7-19.

[25] G. Psacharopoulos. Questionnaire Surveys in Educational Planning, Comparative Education, Vol. 16, No. 2, 159-169.

[26] S.E. Parisean, J.R. McDaniel. Assessing service quality in schools of business, International Journal of Quality \& Reliability Management, Vol. 14, No. 3, 204-218.

[27] V. Teeroovengadum, T.J. Kamalanabhan, A.K. Seebaluck. Measuring service quality in higher education: Development of a hierarchical model (HESQUAL), Quality Assurance in Education, Vol. 24, No. 2, 244-258.

[28] K. Karlgren, M. Lakkala, A. Toom, L. Ilomaki, P. Lahti-Nuuttila, H. Muukkonen. Assessing the learning of knowledge work competence in higher education cross-cultural translation and adaptation of the Collaborative Knowledge Practices Questionnaire, Research Papers in Education, Vol. 35, No. 1, 8-22.

[29] G.R. Pike. The relationship between perceived learning and satisfaction with college: An alternative view, Research in Higher Education, Vol. 34, No. 1, 23-40.

[30] P. Ramsden. A performance indicator of teaching quality in higher education: The Course Experience Questionnaire, Studies in Higher Education, Vol. 16, No. 2, 129-150. 